\title{
Genótipos de batata com baixo teor de açúcares redutores
}

\author{
Arione da S Pereira ${ }^{1,3}$; Roberto Fritsche Neto ${ }^{1,4}$; Roberta da S Silva ${ }^{2}$; Carolina I Bender ${ }^{1}$; Ana Paula \\ Schünemann²; Núbia Marilin L Ferri'i ; João Luiz Vendruscolo ${ }^{1}$ \\ ${ }^{1}$ Embrapa Clima Temperado, C. Postal 403, 96001-970 Pelotas-RS; ${ }^{2}$ UFPEL/FAEM/Depto. Ciência e Tecnologia Agroindustrial, C. \\ Postal 354, 96010-900 Pelotas-RS; ${ }^{3}$ Bolsista CNPq; ${ }^{4}$ Bolsista FAPERGS; arione @ cpact.embrapa.br
}

\section{RESUMO}

Os objetivos deste trabalho foram avaliar genótipos de batata quanto ao teor de açúcares redutores e condições pós-colheita que favoreçam a identificação daqueles com baixo teor. Oito clones, previamente selecionados para cor clara de fritura, e a cultivar Atlantic foram avaliados nos períodos de outono de 2004 e 2005. Os experimentos foram conduzidos na Embrapa Clima Temperado, PelotasRS, Brasil ( $\left.31^{\circ} 52^{\prime} \mathrm{S}, 52^{\circ} 21^{\prime} \mathrm{W}\right)$, em blocos ao acaso com quatro repetições. Em 2004, o teor de açúcares redutores foi quantificado após três condições: cura; quatro semanas refrigerados a $4^{\circ} \mathrm{C}$; e refrigeração seguida por recondicionamento durante duas semanas. Em 2005, os açúcares redutores foram analisados somente após a refrigeração. $\mathrm{O}$ teste $\mathrm{F}$ revelou diferenças significativas entre genótipos para todas as variáveis, exceto para açúcares redutores após a cura dos tubérculos. Os clones 'C-1883-22-97', 'C-1881-1697', 'C-1786-9-96', 'C-1786-7-96' e 'C-1787-14-96' contiveram os teores mais baixos de açúcares redutores. A refrigeração foi a condição que permitiu a identificação de genótipos com baixos teores de açúcares redutores.

Palavras-chave: Solanum tuberosum, processamento, chips, qualidade.

\begin{abstract}
Potato genotypes with low reducing sugar content

The objectives of this work were to evaluate potato genotypes for reducing sugar content and post-harvest conditions that favored the identification of those with low content. Eight potato clones, previously selected for light frying color, and the cultivar Atlantic were evaluated in autumn seasons of 2004 and 2005. The experiments were carried out at Embrapa Clima Temperado, Pelotas-RS, Brazil $\left(31^{\circ} 52^{\prime} \mathrm{S}, 52^{\circ} 21^{\prime} \mathrm{W}\right)$, in a randomized complete block design with four replications. In 2004, the reducing sugar content was quantified after three conditions: curing the tubers; four weeks of refrigerated storage at $4{ }^{\circ} \mathrm{C}$; and refrigeration followed by reconditioning for two weeks. In 2005, the reducing sugars were analyzed only after refrigeration. Besides that the genotypes were evaluated for chip color, dry matter content and physiological defects. The F test revealed significant differences among genotypes for all variables, except for reducing sugar content after tuber curing. 'C-1883-2297', 'C-1881-16-97', 'C-1786-9-96', 'C-1786-7-96' and 'C-178714-96' clones showed the lowest reducing sugar content. The refrigeration was the condition that allowed identification of low reducing sugar genotypes.
\end{abstract}

Keywords: Solanum tuberosum, processing, chips, quality.

(Recebido para publicação em 18 de julho de 2006; aceito em 14 de abril de 2007)

$\mathrm{D}_{\mathrm{i}}^{\mathrm{e}}$ entre as iniciativas essenciais para impulsionar a demanda de batata pré-frita congelada para atrair a preferência dos consumidores brasileiros, destaca-se o desenvolvimento da agroindústria nacional (Boteon et al., 2005). Entretanto, existe uma grande carência de cultivares com características que atendam plenamente os requisitos da indústria e a adaptação à produção no Brasil (Pereira, 2003). A aceitação da batata para processamento na forma de palitos ou chips depende, em grande parte, da cor do produto final. $\mathrm{O}$ fator mais importante na cor de fritura é o teor de açúcares redutores que, quando alto, resulta em produtos escurecidos (Talburt et al., 1975), os quais são rejeitados pelo consumidor (Menéndez et al., 2002). Em batatas para processamento, o teor de açúcares redutores geralmente aceito é abaixo de $0,035 \%$ da massa fresca para chips e
0,12\% para palitos (Stark et al., 2003). Além da característica de fritura de cor clara, as cultivares de batata para o processamento devem apresentar tubérculos com elevado teor de matéria seca (20-24\%) e de preferência sem defeitos fisiológicos (Love, 2000), tais como coração oco, mancha ferruginosa, rachadura e crescimento secundário.

O objetivo deste trabalho foi avaliar genótipos de batata quanto ao teor de açúcares redutores, em função das condições pós-colheita que favoreçam a identificação daqueles com baixo teor.

\section{MATERIAL E MÉTODOS}

Foram avaliados oito clones de batata ('C-1786-6-96', 'C-1786-7-96', 'C1786-9-96', 'C-1787-14-96', 'C-188116-97', 'C-1883-5-97', 'C-1883-22-97' e 'C-1890-1-97'), selecionados para cor clara de fritura no programa de melho- ramento genético da Embrapa Clima Temperado. A cultivar Atlantic, que é utilizada mundialmente pela indústria de processamento de chips, foi incluída como testemunha.

Foram implementados dois experimentos, um em 2004 e outro em 2005 , em blocos ao acaso com quatro repetições, no campo experimental da sede da Embrapa Clima Temperado, Pelotas, RS, Brasil ( $31^{\circ} 52^{\prime} \mathrm{S}$, $\left.52^{\circ} 21^{\prime} \mathrm{W}\right)$. A parcela foi constituída por 15 plantas, espaçadas de $0,30 \mathrm{x}$ $0,80 \mathrm{~m}$. O solo, classificado como Argissolo Vermelho Amarelo Distrófico Típico, foi adubado nos sulcos de plantio com $2.000 \mathrm{~kg} \mathrm{ha}^{-1} \mathrm{de}$ NPK (5-30-10). O controle de doenças e outras práticas foram uniformes e semelhantes às usadas nos plantios comerciais da região. Não houve necessidade de irrigação suplementar em nenhum dos dois experimentos. 
Para o ensaio de 2004, o plantio foi realizado em 10 de março e a colheita em 15 de junho, quando as plantas atingiram total maturidade.

Amostras de tubérculos de cada parcela, classificados como comerciais (diâmetro >45 mm) foram separados para quantificação do teor de açúcares redutores após três condições pós-colheita: a) cura (duas semanas de armazenamento em condições ambiente, com ventilação); b) quatro semanas de armazenamento refrigerado a $4^{\circ} \mathrm{C}$; e c) refrigeração, seguida de recondicionamento por duas semanas em condições ambiente.

A análise do teor de açúcares redutores, efetuada em laboratório da Embrapa Clima Temperado, foi realizada com base no método de SomogyiNelson (Nelson, 1944), com modificações (Pereira \& Campos, 1999). Para a extração dos açúcares, amostras de tubérculos fatiados foram mergulhadas em solução de bissulfito de sódio, neutralizadas com ácido acético glacial e filtradas a vácuo. As amostras foram avaliadas em triplicatas.

Com relação a 2005, o plantio foi efetuado em 9 de março e a colheita em 21 de junho, quando as plantas atingiram a maturidade.

Neste experimento, o teor de açúcares redutores foi analisado somente em tubérculos refrigerados, tendo em vista que em 2004 apenas nesta condição foi possível separar genótipos com teores de açúcares redutores inferiores à testemunha.

Além da avaliação do teor de açúcares redutores, os genótipos foram avaliados quanto à cor de chips, teor de matéria seca, e percentagens de tubérculos rachados, com mancha ferruginosa e com coração oco.

Os chips foram preparados, usando amostras de três tubérculos por parcela. Oito fatias finas (2-3 mm) de cada amostra foram fritas em gordura vegetal hidrogenada, à temperatura inicial de $180^{\circ} \mathrm{C}$, durante o tempo suficiente para cessar a emissão de bolhas de vapor de água do material frito. As avaliações da cor dos chips foram efetuadas de acordo com a tabela de cores de cinco pontos $(1$ = clara a 5 = escura $)$, da Potato Chip and Snack Food Association, dos

Tabela 1. Médias de teor de açúcares redutores em tubérculos de batata em função da simples cura, do armazenamento durante quatro semanas a $4^{\circ} \mathrm{C}$ (refrigerado) e do armazenamento a $4^{\circ} \mathrm{C}$ seguido de recondicionamento durante duas semanas em condições ambiente (recondicionado) (Average content of reducing sugars in potato tubers as a result of simple cura, stored during four weeks under $4^{\circ} \mathrm{C}$ refrigeration and, as a result of storing under $4^{\circ} \mathrm{C}$ followed of reconditioning during two weeks under ambiental conditions (reconditioned). Pelotas, Embrapa Clima Temperado, 2005.

\begin{tabular}{lccccc}
\hline \multirow{2}{*}{ Genótipo } & \multicolumn{3}{c}{$\mathbf{2 0 0 4}$} & & $\mathbf{2 0 0 5}$ \\
\cline { 2 - 4 } \cline { 5 - 6 } & Curado & Refrigerado & Recondicionado & Refrigerado \\
\hline C-1883-22-97 & $0,027 \mathrm{a}^{1}$ & $0,131 \mathrm{a}$ & $0,058 \mathrm{a}$ & \\
C-1881-16-97 & $0,009 \mathrm{a}$ & $0,137 \mathrm{a}$ & $0,077 \mathrm{a}$ & & $0,091 \mathrm{a}$ \\
C-1786-6-96 & $0,019 \mathrm{a}$ & $0,168 \mathrm{ab}$ & $0,091 \mathrm{ab}$ & & $0,248 \mathrm{c}$ \\
C-1786-9-96 & $0,022 \mathrm{a}$ & $0,172 \mathrm{ab}$ & $0,105 \mathrm{ab}$ & & $0,092 \mathrm{a}$ \\
C-1786-7-96 & $0,015 \mathrm{a}$ & $0,187 \mathrm{ab}$ & $0,189 \mathrm{~b}$ & & $0,204 \mathrm{abc}$ \\
C-1787-14-96 & $0,022 \mathrm{a}$ & $0,231 \mathrm{ab}$ & $0,189 \mathrm{~b}$ & & $0,092 \mathrm{a}$ \\
C-1883-5-97 & $0,022 \mathrm{a}$ & $0,253 \mathrm{ab}$ & $0,091 \mathrm{ab}$ & & $0,116 \mathrm{ab}$ \\
Atlantic & $0,026 \mathrm{a}$ & $0,368 \mathrm{bc}$ & $0,080 \mathrm{a}$ & & $0,236 \mathrm{bc}$ \\
C-1890-1-97 & $0,020 \mathrm{a}$ & 0,521 & $\mathrm{c}$ & $0,314 \quad \mathrm{c}$ & 0,343 \\
\hline Média & $0,020 \mathrm{a}$ & $0,241 \mathrm{C}$ & $0,133 \mathrm{~B}$ & $0,170-$ \\
\hline CV (\%) & 37,3 & 43,2 & 39,5 & 40,6 \\
\hline
\end{tabular}

${ }^{1}$ Letras minúsculas iguais, nas colunas, e maiúsculas, na linha, indicam médias sem diferenças estatisticamente detectáveis pelo teste Duncan $(\mathrm{p} \leq 0,05)$ (Means followed by the same small letters in the column and capital in the line did not differ from each other through the Duncan test, $5 \%$ ).

Estados Unidos da América do Norte.

O teor de matéria seca foi determinado segundo a Association Official Analytical Chemistry - AOAC (1970), com algumas modificações (Pereira \& Campos, 1999), em amostras de três tubérculos de cada parcela. De cada tubérculo foram cortadas duas fatias finas (2-3 mm), uma no centro (sentido do diâmetro) e outra no sentido perpendicular (comprimento), que foram picadas a pequenos pedaços. Para análise da matéria seca, uma amostra de 5,0 g de cada parcela foi colocada em cadinho de alumínio para secagem em estufa a vácuo, a $70^{\circ} \mathrm{C}$ por seis horas.

As avaliações da percentagem de tubérculos rachados e com mancha ferruginosa foram efetuadas em amostras de dez tubérculos por parcela. Para avaliação de mancha ferruginosa, os tubérculos foram cortados transversalmente.

Os dados foram submetidos à análise de variância, e as médias comparadas pelo teste de Duncan no nível de 5\% de probabilidade, utilizando o programa Genes (Cruz, 2001). Os dados de percentagem de rachadura e de mancha ferruginosa foram transformados em $\sqrt{(x+0,5)}$ antes da aplicação da análise.

\section{RESULTADOS E DISCUSSÃO}

Em 2004, a média de açúcares redutores foi significativamente mais alta em tubérculos submetidos à refrigeração do que aqueles curados ou recondicionados (Tabela 1). É sabido que as condições ambientais afetam o crescimento e o desenvolvimento das plantas e dos tubérculos, bem como o conteúdo de açúcares nos tubérculos. A exposição dos tubérculos a temperaturas baixas, mesmo no solo ou no armazenamento, propicia a conversão do amido em açúcares, provocando um aumento indesejável no conteúdo de açúcares redutores. Temperaturas altas, por outro lado, diminuem o conteúdo de açúcares redutores nos tubérculos de batata, pela reconversão parcial dos açúcares em amido (Ap Rees et al., 1981; Dale \& Mackay, 1994; Lynch et al., 2003).

Os genótipos apresentaram diferenças significativas $(\mathrm{p} \leq 0,05)$ em teor de açúcares redutores após refrigeração e recondicionamento dos tubérculos (Tabela 1). Não foi detectada diferença significativa em teor de açúcares redutores nos tubérculos após a cura. Seguindo a refrigeração dos tubérculos, os 
Tabela 2. Médias de matéria seca, de tubérculos com rachadura e mancha ferruginosa, e de cor de chips, em função de genótipos de batata e de condições pós-colheita (Average values of dry matter of tubers presenting cracking and ferruginous spots, and of chips, as a result of potato genotypes and after-harvest conditions). Pelotas, Embrapa Clima Temperado, 2005.

\begin{tabular}{lcccc}
\hline Genótipo & $\begin{array}{c}\text { Matéria seca } \\
(\%)\end{array}$ & $\begin{array}{c}\text { Mancha } \\
\text { ferruginosa (\%) }\end{array}$ & $\begin{array}{c}\text { Rachadura } \\
(\%)\end{array}$ & Cor de chips $^{2}$ \\
\hline C-1786-7-96 & $24,6 \mathrm{a}^{1}$ & $5,0 \mathrm{a}$ & $45,0 \mathrm{~b}$ & $1,7 \mathrm{a}$ \\
C-1786-6-96 & $23,7 \mathrm{ab}$ & $5,0 \mathrm{a}$ & $45,0 \mathrm{~b}$ & $1,8 \mathrm{a}$ \\
C-1890-1-97 & $23,7 \mathrm{ab}$ & $17,5 \mathrm{~b}$ & $12,5 \mathrm{a}$ & $2,1 \mathrm{abc}$ \\
C-1881-16-97 & $23,6 \mathrm{ab}$ & $7,5 \mathrm{ab}$ & $40,0 \mathrm{~b}$ & $2,5 \mathrm{c}$ \\
Atlantic & $23,0 \mathrm{abc}$ & $10,0 \mathrm{ab}$ & $10,0 \mathrm{a}$ & $1,8 \mathrm{a}$ \\
C-1883-5-97 & $22,7 \mathrm{abc}$ & $2,5 \mathrm{a}$ & $0,0 \mathrm{a}$ & $2,2 \mathrm{abc}$ \\
C-1787-14-96 & $21,9 \mathrm{bc}$ & $17,5 \mathrm{~b}$ & $5,0 \mathrm{a}$ & $1,9 \mathrm{ab}$ \\
C-1883-22-97 & $21,6 \mathrm{bc}$ & $0,0 \mathrm{a}$ & $0,0 \mathrm{a}$ & $2,3 \mathrm{bc}$ \\
C-1786-9-96 & $21,0 \mathrm{c}$ & $2,5 \mathrm{a}$ & $0,0 \mathrm{a}$ & $1,8 \mathrm{a}$ \\
\hline Média & 22,9 & 7,5 & 17,5 & 2,0 \\
\hline CV (\%) & 7,9 & 5,8 & 9,6 & 19,4 \\
\hline
\end{tabular}

${ }^{1}$ Letras iguais, nas colunas, indicam médias sem diferenças estatisticamente detectáveis pelo teste Duncan ( $\leq \leq 0,05) ;{ }^{2}$ : cor clara a 5: cor escura (Means followed by the same letters in the column did not differ from each other through the Duncan test, $5 \% ;{ }^{2} 1$ : light color to 5: dark color).

clones 'C-1883-22-97', 'C-1881-1697', 'C-1786-6-96', 'C-1786-9-96', ‘C1786-7-96', 'C-1787-14-96' e 'C-18835-97' apresentaram, estatisticamente, os mais baixos teores de açúcares redutores. Quando recondicionados, somente os dois primeiros tiveram níveis significativamente inferiores ao da cultivar 'Atlantic'. Em tubérculos recondicionados, isto é, submetidos à condição que ocorre a diminuição dos níveis de açúcares redutores (Bacarin et al., 2005), os clones 'C-1883-22-97', 'C-1881-16-97', 'C-1883-5-97', 'C1786-6-96' e ‘C-1786-9-96' contiveram açúcares redutores mais baixos, não diferindo da cultivar 'Atlantic'.

Considerando simultaneamente as médias da refrigeração e do recondicionamento, observam-se menores acumulações de açúcares redutores no grupo formado pelos clones 'C-1883-2297', 'C-1881-16-97', 'C-1786-6-96', 'C1786-9-96’ e ‘C-1883-5-97’ (Tabela 1).

As médias de açúcares redutores nas três condições de pós-colheita revelam que após a cura dos tubérculos não houve diferença estatística entre os genótipos (Tabela 1), enquanto na refrigeração houve a formação de três grupos, com separação de clones com níveis de açúcares redutores mais baixos do que a testemunha. A análise de açúcares redutores após o recondicionamento dos tubérculos tam- bém possibilitou a separação dos genótipos, mas não foi suficiente para distinguir os clones com baixos teores de açúcares redutores da testemunha 'Atlantic'. Exceto 'C-1786-7-96' e 'C1787-14-96', os genótipos responderam claramente ao recondicionamento, destacando-se a cultivar 'Atlantic'. Diferenças entre variedades na redução do teor de açúcares redutores por recondicionamento têm sido observadas em outros estudos (Chapper et al., 2004; Bacarin et al., 2005). Estes resultados mostram que a refrigeração dos tubérculos durante quatro semanas foi a melhor condição para a identificação dos genótipos de batata com baixos teores de açúcares redutores.

Em 2005, os clones 'C-1881-16-97', 'C-1786-9-96', 'C-1787-14-96', 'C1883-5-97', 'C-1883-22-97' e 'C-17867-96' apresentaram as médias mais baixas de açúcares redutores (Tabela 1). Mas, apenas 'C-1881-16-97', 'C-17869-96' e 'C-1787-14-96' diferiram da 'Atlantic', em valores inferiores de açúcares redutores.

Considerando os resultados obtidos de tubérculos refrigerados nos dois experimentos, os genótipos que tiveram os teores de açúcares redutores mais baixos foram: 'C-1883-22-97', 'C-188116-97', 'C-1786-9-96', 'C-1786-7-96', 'C-1787-14-96' e 'C-1883-5-97'. O clone 'C-1890-1-97' apresentou, em ambos os anos, a maior percentagem de açúcares redutores.

Em relação aos chips, os clones ' $\mathrm{C}$ 1786-7-96', 'C-1786-6-96' e 'C-17869-96', 'C-1787-14-96', 'C-1890-1-97', 'C-1883-5-97' e a cultivar 'Atlantic' formaram o grupo com médias de escores de cor mais clara (Tabela 2). ' $\mathrm{C}$ 1881-16-97', 'C-1883-22-97', ‘C-18835-97' e 'C-1890-1-97' formaram o grupo de clones com chips mais escuros, mas, mesmo assim, dentro dos padrões de cor clara (escore d"2,5). Os três primeiros foram identificados como os clones com baixo teor de açúcares redutores. Mesmo sendo indubitavelmente estabelecido que o teor de açúcares redutores seja o principal fator para o desenvolvimento da cor de fritura da batata, tem sido demonstrada a influência de alguns aminoácidos e compostos fenólicos na sua intensidade (Khanbari \& Thompson, 1993; Zorzella et al., 2003). Desta forma, não sendo os açúcares redutores totalmente responsáveis pela formação da cor do produto frito, é fundamental que os genótipos sejam avaliados quanto à cor de fritura de chips para uma conclusão mais consubstanciada, vez que a cor de fritura é o caráter de interesse comercial no produto processado.

Os teores de matéria seca de ' $\mathrm{C}$ 1786-7-96', 'C-1890-1-97', 'C-1786-696', 'C-1881-16-97', 'C-1883-5-97' e 'Atlantic' foram estatisticamente os mais elevados. Os demais clones também apresentaram conteúdo de matéria seca compatível com os níveis requeridos pelas indústrias de processamento (e"20\%).

Os defeitos fisiológicos constituem grave limitação para o processamento por fritura da batata para processamento para fritura. As condições climáticas do outono de 2005 favoreceram o aparecimento da mancha ferruginosa e de rachaduras nos tubérculos, todavia, sem a ocorrência de coração oco nos diferentes genótipos (Tabela 2). Houve diferenças significativas entre os genótipos na percentagem de tubérculos com mancha ferruginosa, com o clone ' $\mathrm{C}$-1883-2297' apresentando ausência deste tipo de defeito. Embora 'Atlantic' seja considerada muito suscetível (Henninger et al., 2000), apresentou percentagem relativamente baixa, considerando as condições 
climáticas durante o experimento.

Quanto à ocorrência de tubérculos rachados, houve diferenças significativas entre os genótipos (Tabela 2). 'C1883-22-97', 'C-1883-5-97' e 'C-17869-96' não contiveram este defeito e ' $\mathrm{C}$ 1787-14-96', 'C-1890-1-97' e 'Atlantic' apresentaram baixas percentagens.

Em resumo, constatou-se que os clones 'C-1883-22-97', 'C-1881-1697', 'C-1786-9-96', 'C-1786-7-96', 'C1787-14-96' e 'C-1883-5-97' contiveram os mais baixos níveis de açúcares redutores. Destes, apenas 'C-1883-5-97' e 'C-1786-7-96' podem ser alocados em grupo de genótipos com chips mais claros e com teor de matéria seca mais elevada, embora os demais tenham expressado níveis de qualidade aceitáveis; ' $\mathrm{C}$ 1883-22-97' não teve tubérculos com mancha ferruginosa, ao contrário de ' $\mathrm{C}$ 1883-5-97', 'C-1786-9-96', 'C-178714-96' e 'C-1881-16-97' que apresentou, mas em baixas percentagens, enquanto 'C-1787-14-96' revelou a maior incidência; 'C-1883-22-97', 'C-1883-597' e ‘C-1786-9-96' não contiveram tubérculos rachados.

Concluindo, a refrigeração dos tubérculos durante quatro semanas permitiu a identificação dos genótipos 'C-1883-2297', 'C-1881-16-97', 'C-1786-9-96', 'C1786-7-96' e 'C-1787-14-96' como de baixos teores de açúcares redutores. Entretanto, considerando também os outros caracteres avaliados, 'C-1883-22-97', 'C-1786-9-96' e 'C-1883-5-97' foram os clones de melhor qualidade.

\section{AGRADECIMENTOS}

À equipe de apoio ao Programa de Melhoramento Genético de Batata e do Laboratório de Tecnologia de Alimentos da Embrapa Clima Temperado, pelas contribuições na execução dos experimentos, e à CAPES, CNPq e FAPERGS, pelas bolsas concedidas.

\section{REFERÊNCIAS}

ASSOCIATION OF OFFICIAL ANALYTICAL CHEMISTS (Gaithersburg, Estados Unidos). 1970. Official methods of analysis. $11^{\mathrm{a}}$ ed. Washington: 1015p.

AP REES T; DIXON WL; POLLOCK CJ; FRANK F. 1981. Low temperature sweetening of higher plants. In: FRIEND J; RHODES MJC (eds). Recent advances in the biochemistry of fruits and vegetables. New York: Academic Press. p. 41-44.

BACARIN MA; FERREIRA LS; DEUNER S; BERVALD CMP; ZANATTAER; LOPES NF. 2005. Carboidratos não estruturais em tubérculos de batata recondicionados após o armazenamento sob diferentes temperaturas. Horticultura Brasileira 23: 799-804.

BOTEON M; SILVA RC da; DELEO JPB. 2005. Uma nova receita para a bataticultura. Hortifruti Brasil 4: 7-13

CHAPPER M; LOUREIRO ME; MOSQUIM PR; ARAUJO WL; PEREIRA A da S; FINGER FL; SIMÕES AN. 2004. Mudanças metabólicas após recondicionamento a $15^{\circ} \mathrm{C}$ de tubérculos de batata armazenados a baixa temperatura. Horticultura Brasileira 22: 700-705.

CRUZ CD. 2001. Programa Genes - versão Windows. Viçosa: Ed. UFV. 642p.

DALE MFB; MACKAY GR.1994. Inheritance of table and processing quality. In BRADSHAW JE; MACKAY GR (eds). Potato genetics. Wallingford: CAB International. p. 285-315.
HENNINGER MR; STERRETT SB; HAYNES KG. 2000. Broad-sense heritability and stability of internal heat necrosis and specific gravity in Tetraploid potatoes. Crop Science 40: 977-984.

KHANBARI OS; THOMPSON AK. 1993. Effects of amino acids and glucose on the fry colour of potato crisps. Potato Research 36: 359-364.

LOVE SL. 2000. Important quality characteristics in breeding processing potatoes. In: WORLD POTATO CONGRESS, 4. Proceedings... Amsterdam: Wageningen Press. p. 261-266.

LYNCH DR; KAWCHUK R; YADA R; ARMSTRONG JD. 2003. Inheritance of the response of fry color to low temperature storage. American Potato Journal 80: 341-344.

MENÉNDEZ CM; RITTER E; SCHÄFERPREGL R; WALKEMEIER B; KALDE A; SALAMINI F; GEBHARDT C. 2002. Cold sweetening on diploid potato: Mapping quantitative trait loci and candidate genes. Genetics 162: 1425-1434.

NELSON NA. 1944. A photometric adaptation of Somogyi method for the determination of glucose. Journal of Biological Chemistry 135: 375.

PEREIRA A da S; CAMPOS AD. 1999. Teor de açúcares em genótipos de batata (Solanum tuberosum L.). Ciência Rural 29: 13-16.

PEREIRA A da S. 2003. Melhoramento genético. In: PEREIRA A da S; DANIELS J (eds). $O$ cultivo da batata na Região Sul do Brasil. Brasília: Embrapa Informação Tecnológica. p. 105-124.

STARK JC; OLSEN N; KLEINKOPF GE; LOVE SL. 2003. Tuber quality. In: STARK JC; LOVE SL (eds). Potato production systems. Aberdeen: University of Idaho. p. 329-343.

TALBURT WF; SCHWIMMER S; BURR HK. 1975. Structure and chemical composition of the potato tuber. In: TALBURT WF; SMITH $\mathrm{O}$ (eds). Potato processing. Westport: The AVI Publishing. p. 11-42.

ZORZELLA CA; VENDRUSCOLO JLS; TREPTOW RO; ALMEIDA TL. 2003. Caracterização física, química e sensorial de genótipos de batata processados na forma de chips. Brazilian Journal of Food Technology 6: 15-24. 